\title{
Introductory Remarks by the President and CEO of the Lymphatic Education and Research Network (LE\&RN)
}

\author{
William Repicci, MA, President \& CEO
}

\begin{abstract}
D URING OUR CAREERS, there are moments we hope to look back on as being seminal in their impact. In the case of LE\&RN establishing the first-ever Centers of Excellence in the Diagnosis and Treatment of Lymphatic Diseases, one does not need to wait for history to make this pronouncement.

The dream of establishing Centers of Excellence in lymphatic medicine was always part of the LE\&RN playbook. After all, LE\&RN's mission is to fight lymphatic diseases through education, research, and advocacy. However, it would take $>20$ years of setting the stage before this could become a reality. First, researchers would need to be convinced to direct their energies to lymphatics; the medical profession that remained uneducated about these diseases would need to embrace the field; and finally, those living with lymphatic diseases - and their loved ones-would have to find their voices and become fierce advocates for the cause. It is a tribute to all those who have joined this fight over LE\&RN's 22 years as an organization that we recently announced 25 Centers of Excellence around the world.

I could not begin to thank all those who played a role in reaching this moment. However, I would like to recognize those who played a dynamic role in this final realization of the centers. First, our thanks to the Steering Committee that developed the initial program standards: Drs. David Chang, Joseph Dayan, Ketan Patel, Stanley Rockson, Dhruv Singhal, and Melissa Aldrich, $\mathrm{PhD}$, who brilliantly chaired this committee. Further thanks extend to Dr. Aldrich and Professor Peter Mortimer who chaired the Global Oversight Committee made up of 12 international leaders in the field who would review center applications.
\end{abstract}

Further kudos go to LE\&RN staff that has managed every step of this year-long process to guarantee compliance and a bias-free outcome. Finally, congratulations to all of the speakers at this first Centers of Excellence Summit. Thanks to your dedication, you are transforming the experience of those needing treatment for lymphatic diseases.

Our work is only beginning. LE\&RN is now sending out a request for new letters of inquiry from institutions interested in becoming centers. Furthermore, we invite all of those receiving and offering services at our centers to apply to be members of our affiliate boards. These boards are being established at every institution to guarantee an ongoing conversation between service provider and those receiving those services. You can apply to join an affiliate board by writing LE\&RN at: COE@lymphaticnetwork.org.

In closing, a special thanks to Dr. Stanley Rockson. Not only is Dr. Rockson a cofounder of LE\&RN, this Virtual Summit was his brainchild. He has worked tirelessly with LE\&RN staff to organize this event that represents a milestone in the annals of lymphatic medicine.

Address correspondence to: William Repicci, MA Lymphatic Education and Research Network 261 Madison Avenue 9th Floor New York, NY 10016

USA

E-mail: wrepicci@lymphaticnetwork.org

Lymphatic Education and Research Network, New York, New York, USA. 